\title{
Imaginar el futuro en medio del conflicto en el Magdalena Medio, Colombia*
}

\author{
Jefferson Jaramillo Marín** \\ Erika Paola Parrado Pardo ${ }^{* * *}$ \\ Mery Edith Rodríguez Arias ${ }^{* * * *}$ \\ Mario Roberto Solarte Rodríguez $z^{* * * * *}$
}

Artículo de reflexión sobre el potencial transformador de las memorias

en el Magdalena Medio, Colombia.

Recibido: 22 de noviembre de 2020

Evaluado: 11 de febrero de 2021

Aceptado: 11 de febrero de 2021

Publicado: 1 de julio de 2021

\footnotetext{
* Artículo derivado del proyecto Memoria de Futuro en el Magdalena Medio (ID 5767). La investigación fue financiada por la Pontificia Universidad Javeriana entre 2014 y 2017 y contó con el apoyo de investigadores adscritos a cuatro grupos de investigación reconocidos por Minciencias: Ciencia de la información, Sociedad y Cultura (categoría A), Estado, Conflictos y Paz (categoría A1), Pensamiento Crítico y Subjetividad (categoría A1), Política Social y Desarrollo (categoría A1). La investigación contó con el cumplimiento de un protocolo ético y de consentimientos informados de quienes participaron. Los autores agradecen a los sociólogos Germán Erazo y Juan Pablo Arciniegas por la contribución en el procesamiento de la información proveniente de las entrevistas.

** Profesor titular, Departamento de Sociología, Pontificia Universidad Javeriana, Colombia. Doctor en Investigación en Ciencias Sociales.

Correo electrónico: jefferson.jaramillo@javeriana.edu.co

ORCID: http://orcid.org/0000-0002-0016-7631

*** Profesora de cátedra, Departamento de Historia, Pontificia Universidad Javeriana, Colombia. Magíster en Estudios de Paz y Resolución de Conflictos.

Correo electrónico: eparrado@javeriana.edu.co

ORCID: http://orcid.org/0000-0001-5434-1132

${ }^{* * * *}$ Investigadora y facilitadora del Observatorio de Paz, Colombia. Magíster en Análisis y Resolución de Conflictos.

Correo electrónico: meryrodriguez22@gmail.com

ORCID: https://orcid.org/0000-0001-7007-9429

***** Profesor asociado, departamento de Filosofía, Pontificia Universidad Javeriana, Colombia. Doctor en Filosofía.

Correo electrónico: rsolarte@javeriana.edu.co

ORCID: https://orcid.org/0000-0001-8848-7471
}

Hallazgos

ISSN: 1794-3841 | e-ISSN: 2422-409X | DOI: https://doi.org/10.15332/2422409X

Vol. 18 N. ${ }^{\circ} 36 \mid$ julio-diciembre del 2021 
Citar como:

Jaramillo, J., Parrado, E., Rodríguez, M. y Solarte, M. (2021). Imaginar el futuro en medio del conflicto en el Magdalena Medio, Colombia. Hallazgos, 18(36), 323-363. https://doi.org/10.15332/2422409X.6307

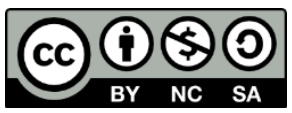

\section{Resumen}

Los ejercicios institucionales y comunitarios sobre las memorias del conflicto colombiano han adquirido protagonismo en las dos últimas décadas. En medio de las luces y sombras de este boom memorial, en este artículo de reflexión se plantea la pregunta: ¿en qué sentido el recurso a la memoria permite comprender las maneras locales de navegar presentes convulsos e imaginar escenarios de futuro individuales y colectivos cuando se ha sido víctima de desaparición o desplazamiento forzados? La investigación de la cual deriva el artículo se basó en un trabajo cualitativo, interdisciplinario y participativo desarrollado entre 2014 y 2017 en la región del Magdalena Medio, Colombia, con personas desplazadas y familiares de desaparecidos. La experiencia de campo y el diálogo con los estudios sociales y culturales de la memoria permiten vislumbrar que, aunque los presentes de las personas con las que conversamos están llenos de incertidumbre, la imaginación social del porvenir es un recurso cotidiano para enfrentar contextos afectados o fracturados por violencias diversas. La principal conclusión es que las memorias que se reconocen en su potencial transformador abogan por la activación de la esperanza local y la ilusión comunitaria, más que por ser solo ejercicios reconstructivos de las afectaciones sufridas.

Palabras clave: Conflicto armado; Futuro; Imaginación del futuro;

Memoria colectiva; Potencial transformador de la memoria;

Transformación social. 


\section{Imagining the future in the midst of conflict in Magdalena Medio, Colombia}

\section{Abstract}

Institutional and community exercises on the memories of the Colombian conflict have gained prominence in the last two decades. In the midst of the lights and shadows of this memorial boom, this reflection article poses the question: in what sense does the recourse to memory allow us to understand local ways of navigating the convulsive present and imagining individual and collective future scenarios when one has been the victim of disappearance or forced displacement? The research from which the article derives was based on a qualitative, interdisciplinary and participatory work developed between 2014 and 2017 in the Magdalena Medio region (Middle Magdalena Region, Colombia) with displaced persons and relatives of the disappeared. The field experience and the dialogue with the social and cultural studies of memory allow us to perceive that, although the present of the people with whom we talk are full of uncertainty, the social imagination of the future is a daily resource to face contexts affected or fractured by various types of violence. The main conclusion is that the memories that are recognized in their transformative potential advocate for the activation of local hope and community illusion, rather than being only reconstructive exercises of the affections suffered.

Keywords: Armed conflict; Future; Imagination of the future;

Collective memory; Transforming potential of memory; Social transformation.

\section{Imaginar o futuro em meio ao conflito em Magdalena Medio, Colômbia}

\section{Resumo}

Exercícios institucionais e comunitários sobre as memórias do conflito colombiano ganharam protagonismo nas últimas duas décadas. Em meio 
às luzes e sombras desse boom memorial, este artigo reflexivo levanta a questão: em que sentido o recurso à memória permite compreender as formas locais de navegar presentes convulsivos e imaginar cenários de futuros individuais e coletivos quando você foi vítima de desaparecimento ou deslocamento forçado? A pesquisa da qual deriva o artigo baseou-se em um trabalho qualitativo, interdisciplinar e participativo desenvolvido entre 2014 e 2017 na região de Magdalena Medio, Colômbia, com pessoas deslocadas e familiares de desaparecidos. A experiência de campo e o diálogo com os estudos sociais e culturais da memória permitem vislumbrar que, embora os presentes das pessoas com quem conversamos sejam cheios de incertezas, o imaginário social do futuro é um recurso diário para elas enfrentarem os contextos afetados ou fraturados por violências diversas. A principal conclusão é que as memórias reconhecidas em seu potencial transformador preconizam a ativação da esperança local e da ilusão comunitária, mais que serem apenas exercícios reconstrutivos dos efeitos sofridos.

Palavras-chave: Conflito armado; Futuro; Imaginação do futuro; Memória coletiva; Potencial transformador da memória; Transformação social.

\section{Introducción}

En las dos últimas décadas los ejercicios institucionales y sociales sobre la memoria y las memorias de la violencia y el conflicto en Colombia se hicieron comunes, aunque los trabajos en torno al tema se remontan hasta los años setenta en las luchas del movimiento de los derechos humanos (Tamayo, 2019; Sánchez, 2020). Como parte de este protagonismo, el sintagma memoria histórica ganó en legitimidad normativa en Colombia en medio de un conjunto de políticas de evidencia (Ruiz et ál., 2020), enfocadas en el esclarecimiento de las violencias y las afectaciones comunitarias (Riaño y Uribe, 2016; Schuster, 2017; Castro y Erazo, 2019). El boom de las memorias, como habitualmente se denomina a lo sucedido 
en el país, se convirtió en nutriente de agendas públicas o aliciente de recursos de cooperación en el denominado proceso de Justicia y Paz (2005-2011) y en aliado de la paz durante los recientes diálogos de La Habana (Sánchez, 2014).

A la par se incorporó la memoria como categoría teórica y recurso metodológico al acervo semántico de centros de estudio, observatorios de investigación, activistas y académicos, antes dedicados a otros menesteres. La memoria como política se deslizó desde las demandas históricas del movimiento de los derechos humanos hacia múltiples formas de denuncia organizativa para la exigibilidad de garantías de justicia, reparación y no repetición (Gómez, 2013). No obstante, el espacio para la reconstrucción o activación de las memorias del conflicto no ha estado exento de disputas, luces y sombras en torno a lo acontecido y lo representado sobre los pasados y presentes de las violencias recientes en el país (Blair, 2011; Castaño et ál., 2018; Buchely, 2020; Jaramillo y Torres, 2019).

Uno de los asuntos sobre los cuales no se ha reflexionado lo suficiente en el marco de este boom memorial en Colombia es sobre el potencial transformador de la memoria, es decir, sobre cómo estas comunidades navegan sus presentes llenos de incertidumbre e imaginan futuros posibles, algo que está interesando cada vez más al campo emergente de los estudios de futuro (Visacovsky, 2019). Con base en los acumulados investigativos de una experiencia interdisciplinar de corte cualitativo y participativo desarrollada entre 2014 y 2017 en la región del Magdalena Medio, Colombia, donde conversamos e interactuamos con pobladores urbanos de barrios populares de Barrancabermeja, como 22 de Marzo, El Diamante y Bosques de la Cira, y habitantes rurales de San Pablo, Sur de Bolívar, en este artículo proponemos discutir la siguiente pregunta: ¿̇en qué sentido el recurso a la memoria permite comprender las maneras locales de navegar presentes convulsos e imaginar escenarios de futuro 
individuales y colectivos cuando se ha sido víctima de desaparición o desplazamiento forzados?

Además de las conversaciones ${ }^{1}$, la investigación diseñó espacios de trabajo colaborativo para la elaboración de líneas de tiempo, cartas a futuro, árboles de la vida, historias de vida y un documental. La experiencia de campo y la emergencia teórica que esta proporcionó, así como las reflexiones teóricas derivadas de los estudios sociales y políticos de la memoria en el país, tienen la intención de amplificar el debate sobre esa pregunta, pero también sobre una tesis socorrida hoy: la de cómo activar la imaginación del futuro en contextos afectados o fracturados/dislocados por violencias diversas (Castillejo, 2017, 2019; Redepaz et ál., 2016). Quizá también permita pensar posibilidades metodológicas y categoriales en torno al trabajo regional sobre las memorias, no solo en clave reconstructiva del dolor, sino también de activación de la esperanza en medio de la incertidumbre cotidiana de las comunidades.

Es importante anotar que los investigadores que hicieron parte del proyecto "Memoria de Futuro en el Magdalena Medio" evitaron formular preguntas que pudieran generar revictimización en las personas entrevistadas. Por ética del cuidado, y con miras a garantizar el anonimato de los participantes, no se citan los nombres de quienes contribuyeron en el ejercicio investigativo.

El artículo está organizado de la siguiente manera: como apertura conceptual, reflexionamos sobre la relación entre memoria, presentes convulsos y preguntas por el futuro. Pasamos luego a una parte más contextual, donde mostramos cómo se puede comprender/interpretar la región del Magdalena. A propósito de algunos de los resultados obtenidos

\footnotetext{
${ }^{1}$ Para este artículo nos basamos en un corpus de referencia de 31 entrevistas y testimonios, aunque al final no lo citamos todo.
}

Hallazgos

ISSN: 1794-3841 | e-ISSN: 2422-409X | DOI: https://doi.org/10.15332/2422409X 
en el trabajo investigativo, abordamos los paisajes de lo cotidiano y reflexionamos sobre cómo personas que han sido afectadas por la desaparición y el desplazamiento forzados navegan sus presentes convulsos e imaginan el futuro. Finalmente, llegamos a la práctica metodológica del proyecto, sobre lo que esta activó y las preguntas que aún resuenan.

\section{La memoria, los presentes convulsos y las preguntas por el futuro}

Con cierta regularidad se dice y se asume que la memoria está conectada con experiencias del pasado reciente que resultan significativas para alguien en el presente. También se asume el pasado como ese país extraño al que se quiere retornar - parafraseando al escritor David Lowenthal (1985) -, donde la memoria es una especie de médium para hacerlo. Sin embargo, dos preguntas habitan la reflexión reciente sobre estos temas, al menos desde la experiencia situada en una región como el Magdalena Medio: 1) ¿la memoria puede ayudar a comprender las maneras como las comunidades locales imaginan sus futuros posibles?, 2) ¿esta imaginación tiene sentido y puede llevarse a cabo en medio de las fracturas presentes y continuidades de las violencias?

Por ahora diremos que la memoria es, por excelencia, un ámbito de lo cotidiano - con toda la densidad política que esto implica -, en el que se conecta la dimensión de la experiencia (aquello que ha sucedido a alguien), con la de la expectativa - lo que aún no es, pero se presenta como guía de acción (Vignolo et ál., 2017) - . Siguiendo a Reinhard Koselleck (1993)², lo que se sugiere es que la experiencia es acumulada, recordada, traída al presente - pero también vivida como experiencia límite-, y la expectativa

\footnotetext{
2 Para una actualización crítica de esta perspectiva, se recomienda el trabajo de Arboleda et ál. (2020).
}

Hallazgos

ISSN: 1794-3841 | e-ISSN: 2422-409X | DOI: https://doi.org/10.15332/2422409X 
es objeto de espera, construcción, ensoñación e imaginación. En la articulación de ambas es posible pensar que si bien la memoria dice mucho sobre el pasado que pretende recobrar, también permite entender la incertidumbre presente y la imaginación del porvenir desde quien recuerda (Cruz, 2013; Belvedresi, 2013).

En dicha articulación, como reconocen varios analistas, se pueden habilitar tantas visiones sobre los pasados como experiencias presentes y futuras de los sujetos (Jelin, 2002; Traverso, 2007; Arboleda et ál., 2020). No pocas de esas experiencias subjetivas tienen conexión directa -además del dolor y el trauma - con dimensiones como la esperanza, los anhelos, los afectos, la promesa, la agencia, la ilusión, aspectos sobre los cuales no se reflexiona tanto desde el campo de los estudios sociales y políticos de la memoria, o al menos no como se esperaría. En el caso colombiano, son varios los analistas y colectivos que vienen sugiriendo y alertando sobre la necesidad de pensar y trabajar en torno a ello, especialmente sobre unas memorias que permitan comprender las condiciones como las comunidades imaginan - en presentes convulsos - escenarios de futuro, y no solo cómo construyen narrativas sobre lo doloroso.

Desde hace ya varios años, la psicología social/comunitaria/política, a través de los trabajos de Molina (2010), Villa et ál. (2007), Tovar (2019), Castro y Erazo (2019), viene haciendo eco de este llamado, invitando a transitar desde una mirada de la víctima como agente de dolor hacia un reconocimiento pleno de ella como actor social, que construye en todo momento subjetividades políticas o agencias ético-políticas en clave de presentes transformadores y posibilidades futuras 3 . Este llamado lo hizo Ortega (2008) en su momento, sugiriendo - en conexión con las propuestas de la antropóloga Veena Das - rehabitar la cotidianidad desde

\footnotetext{
${ }^{3}$ Varios de los trabajos compilados en el libro Psicología Política y Procesos de paz en Colombia vuelven y reiteran este llamado (Díaz y Bravo, 2019).
}

Hallazgos

ISSN: 1794-3841 | e-ISSN: 2422-409X | DOI: https://doi.org/10.15332/2422409X 
la dignidad de los afectados por nuestras violencias. Más recientemente, plataformas organizativas como Redepaz (Redepaz et ál., 2014) se han preguntado por la dimensión transformadora de la memoria, o Solarte y Rodríguez (2017) por memorias en perspectiva amorosa, o Torres et ál. (2017) por memorias que evidencien las estrategias de futuro que construyen comunidades sobrevivientes en los márgenes nacionales. Las preguntas por la imaginación de escenarios de futuro, pero también por cómo navegar presentes convulsos, no parecen, por tanto, cuestiones menores ni para la academia ni para nuestras condiciones históricas caracterizadas por "enormes capas de devastación" generadas por las violencias pasadas y presentes (Castillejo, 2019). En ese sentido, temas como el futuro, el porvenir y las maneras de enfrentarlos localmente desde el presente habitan cada vez más los trabajos con la memoria en el país. ¿Pero cómo lo están haciendo? Por una parte, se sugiere el reconocimiento de las trazas cotidianas y a pequeña escala de aquello que las personas recrean para sobrevivir en medio de la incertidumbre de un país que parece no acabar de pasar la página de la guerra.

Por otra parte, se comprenden los múltiples sentidos sobre cómo se navega territorialmente desde el presente hacia el futuro, a contrapelo de lo que pretende decirnos o imponernos, a gran escala, la tecnopolítica transicional de la paz, que tiende a imponer modelos o moldes de presente y futuro (Castillejo, 2017, 2019) o guiones emocionales con los cuales el Estado termina administrando a escalas local y regional la paz y la memoria (Buchely, 2020).

Y por otra, se percibe el valor de las memorias como narraciones abiertas (Castaño y Jurado, 2019) y el sentido profundo - aunque no exento de dificultades - de las memorias como recursos experienciales no meramente como dispositivos retrospectivos, sino como experiencias productivas en el presente y abiertas al futuro (Rabe, 2019). Es decir, 
estas perspectivas sugieren ser más conscientes, en el trabajo con las memorias, de los proyectos cotidianos, de las apuestas territoriales, de las esperanzas y los anhelos de fortalecimiento organizativo, de los sentidos de reafirmación de la vida en su integralidad política, cultural, física, económica, natural, territorial, ecológica e íntima (Escobar, 2015)4. El proyecto que da lugar a este artículo partió de reconocer, en la bisagra entre el espacio experiencial y el horizonte de expectativas de las personas, cuatro dimensiones en la dirección antes mencionada: 1) lo que ellas activan acerca de su vida personal o familiar antes de los hechos violentos de la desaparición o el desplazamiento forzados; 2) lo que el hecho violento hizo a sus proyectos vitales, personales, comunitarios y organizativos5; 3) lo que les permitió el afrontamiento, los tránsitos y la reafirmación de la vida; 4) lo que imaginan acerca de un futuro tanto compartido como personal. En esa confluencia, el equipo fue consciente de que el trabajo desde la memoria, y con ella, podía percibir cómo las comunidades locales iban narrando sus opciones de futuro desde presentes complejos por la continuidad del conflicto armado y político en las zonas. Estas dimensiones, a su vez, surgieron de conversaciones previas en esta región con los socios locales del proyecto y también de los acumulados investigativos del equipo que coordinó el proyecto.

Tras varios años de cierre del proyecto, aunque dichas pretensiones no han perdido su horizonte comprehensivo, siguen pendientes y resonando para nosotros como equipo algunas preguntas: ¿̇cómo reconocer o percibir,

\footnotetext{
${ }^{4}$ En esa dirección se encuentra desde hace varias décadas el trabajo de memoria del Proceso de Comunidades Negras (PCN) en el Pacífico colombiano. Para una ampliación de este, véase PCN (2015). Sobre el tema de las memorias en clave de defensa de la vida e imaginación del futuro en el Pacífico, se recomienda Louidor y Jaramillo (2020). ${ }^{5}$ El proyecto del cual deriva el artículo se propuso "potenciar una comunidad de memoria regional" para construir metodologías conjuntas de formación de facilitadores y multiplicadores en actividades de apoyo psicosocial, basadas en la construcción de lazos de confianza y escucha activa. Un balance de sus alcances y límites no se ha hecho dentro del proyecto.
}

Hallazgos

ISSN: 1794-3841 | e-ISSN: 2422-409X | DOI: https://doi.org/10.15332/2422409X 
desde la cotidianidad comunitaria, las trazas de imaginación social del porvenir?, ¿̇cómo intuir cuándo es transformador un ejercicio de memoria para una comunidad, dada la mediación institucional-académica?

\section{Un poco de contexto regional}

El Magdalena Medio es una región que cobija más de 30 municipios y 8 departamentos ${ }^{6}$ y se ubica en el valle central del río Magdalena. Es básicamente una subregión donde confluyen a escala geopolítica el oriente y el occidente, una parte de la zona andina y el Caribe colombiano. La inclusión de más o menos municipios dependerá de la forma como se "imagine" institucionalmente la subdivisión regional y el trazado de las relaciones económicas, políticas y culturales. Por ejemplo, la Comisión de la Verdad en su mandato de esclarecimiento, convivencia y no repetición, habla de 44 municipios, mientras que el informe del Centro Nacional de Memoria Histórica (CNMH, 2017) menciona 31 municipios (figura 1). Esta zona, al igual que otras en el país, ha sido protagonista de una larga historia de iras, dolores y esperanzas, y mucho se ha escrito y reflexionado sobre ella. Con el ánimo más de hacer una condensación analítica, no de exhaustividad historiográfica -imposible de lograr en este escrito-, nos referimos a tres claves con las cuales se puede contextualizar esta región.

La primera clave sugiere que el Magdalena Medio es un territorio-frontera, rebelde y periférico, donde se constituyeron sociedades que fueron erigiéndose a partir de la supervivencia, la resistencia y la confrontación frente al desprecio centralista (Murillo, 1999; Molano, 2009; Archila et ál., 2006). En su condición de territorio fronterizo se ha caracterizado, por tanto, por constantes flujos poblacionales en torno al petróleo y otros

\footnotetext{
${ }^{6}$ Esta subregión cubre, en mayor medida, los departamentos de Antioquia, Bolívar, Boyacá, Cesar y Santander y, en menor medida, los de Caldas, Cundinamarca y Tolima.
}

Hallazgos

ISSN: 1794-3841 | e-ISSN: 2422-409X | DOI: https://doi.org/10.15332/2422409X 
movimientos poblacionales derivados de despojos y violencias acontecidas dentro del país, que fueron llevando a que muchos desarraigados optaran por esta zona como una especie de tierra promisoria. El corazón económico y político de esta región ha sido la ciudad de Barrancabermeja ${ }^{7}$, la cual se ha nutrido de legados migratorios costeños, santandereanos, antioqueños y cundiboyacenses (Pita, 2016, p. 72; CNMH, 2017; Molano, 2009; Archila et ál., 2006).

Figura 1. Mapa de la Región del Magdalena con los departamentos más centrales: Antioquia, Bolívar, Cesar y Santander.

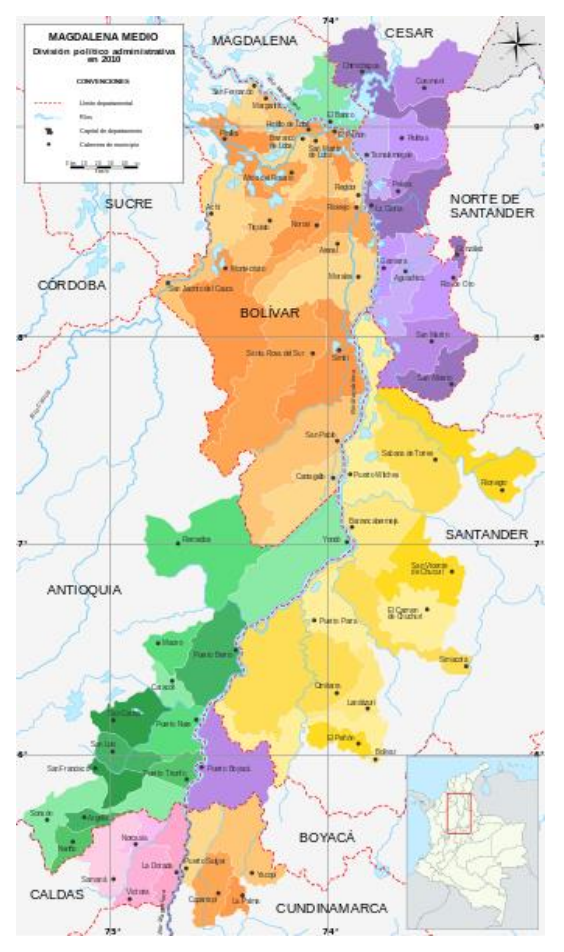

Fuente: Wikimedia Commons (2020). Licencia Creative Commons AttributionShare Alike 4.0 International. 7 Aunque también han tenido papel protagónico otras ciudades como Puerto Boyacá,
en Boyacá, y Puerto Berrío, en Antioquia. 
La segunda clave sugiere que el Magdalena Medio es expresión de un proceso doble de invención regional: por parte del Estado y por parte de los tejidos organizativos-comunitarios. El Estado ha imaginado esta región con la intención de delimitarla como un espacio propicio para las dinámicas de expansión del capital y de explotación de sus recursos (Archila et ál., 2006; Molano, 2009; Murillo, 1999). Las organizaciones la han imaginado, por su parte, como una región posible para la vida y para la gente. De hecho, si hay una región del país donde se siente la energía de resistencia organizativa, es el Magdalena Medio. Esta resistencia regional hunde sus raíces en el mundo indígena, en el papel de la Iglesia católica, y se materializa especialmente en muchas plataformas organizativas y en sus laboratorios de desarrollo y paz (Katz, 2004; Solarte, 2004; Angarita, 2007; De Roux, 1999; Barreto, 2009; CNMH, 2017) ${ }^{8}$.

Y la tercera clave es la que subraya la condición del Magdalena Medio como región ordenada por la guerra, es decir, no solo es un territorio imaginado, sino disputado desde los años setenta del siglo XX por diversos actores armados (Estado, guerrillas, paramilitares, empresas de narcotráfico) e intereses privados (multinacionales) que, mutando en el tiempo, han edificado unos órdenes económicos y sociales violentos, los cuales, aunque existan distintos experimentos institucionales y sociales de paz, siguen funcionando tras un manto de silencio, de impunidad y temor

\footnotetext{
${ }^{8}$ Si quisiéramos hacer un breve paneo, por décadas, de la enorme energía organizativa en esta región, habría que mencionar, por ejemplo, desde los años setenta, el papel protagónico del Comité Privado de Desarrollo, la Organización Femenina Popular, el Movimiento Cívico, Obrero y Campesino. Respecto a los ochenta, no habría que olvidar la influencia organizativa de la Coordinadora de Solidaridad, la Coordinadora del Sector Nororiental, la Coordinadora Popular, la Comisión de Veeduría, la Coordinadora Campesina del Magdalena Medio, el Comité Regional para la Defensa de los Derechos Humanos (Credhos), la Asociación de Trabajadores Campesinos del Carare y el Frente Común por la Vida, la Paz y la Democracia. En los noventa serán claves el Comité Cívico de Convivencia Ciudadana, el Comité Nacional Antisicarial, el Consejo de Desarrollo Socio-Económico (Codes), la Coordinadora Popular de Barrancabermeja, el Programa de Desarrollo y Paz para el Magdalena Medio y el Movimiento Regional por la Paz. Varias de estas experiencias continúan hasta la actualidad.
}

Hallazgos 
creciente de las comunidades. Estos órdenes, a la vez que regulan la vida, la fracturan y aniquilan (Archila et ál., 2006; CNMH, 2017; Molano, 2009). Dos de los mecanismos utilizados o legitimados por estos órdenes para controlar y devastar la vida en esta región han sido, sin lugar a duda, la desaparición y el desplazamiento forzados.

A propósito de esto último, el Observatorio de Memoria y Conflicto del CNMH ha calculado que entre 1975 y 2013 hubo 1057 desapariciones forzadas en la ciudad de Barrancabermeja y 462 desapariciones forzadas para San Pablo, sur de Bolívar, dos de los epicentros donde focalizamos nuestra investigación. Según esta fuente, los grupos paramilitares fueron responsables de este hecho en casi el $39 \%$. Sin embargo, el porcentaje de actores no identificados o desconocidos hasta el momento es del $45 \%$ (muy probablemente Estado, guerrillas y otros actores). Por otra parte, según datos del Registro Único de Víctimas y en el marco de la Ley 1448 de 2011, son reconocidas como víctimas de desplazamiento forzado 40632 víctimas en Barrancabermeja y 42055 víctimas en San Pablo. De lejos, para la región, así como para los barrios (por ejemplo, 22 de Marzo, Bosques de la Cira, El Diamante) y las zonas rurales (por ejemplo, Pozo Azul) donde trabajamos, estos han sido los mayores hechos de afectación para las poblaciones y comunidades que los habitan.

\section{Los paisajes de lo cotidiano: rehabitando el presente, navegando el porvenir}

Aunque el Magdalena Medio podría ser interpretado como un territorio de frontera y de disputas, las conversaciones sostenidas con pobladores locales entre 2014 y 2017 permiten situar, en la escena de la memoria regional, una clave profunda que ayuda a responder la pregunta central de esta investigación, basada en el recurso de la memoria para comprender las maneras locales de navegar presentes convulsos e imaginar escenarios 
de futuro individuales y colectivos cuando se ha sido víctima de desaparición y desplazamiento forzados. Tal clave la encontramos en los paisajes de lo cotidiano. Esta categoría ha sido perfilada en otros estudios dedicados a percibir las espacialidades cotidianas de las comunidades que son afectadas por diversas formas de acaparamientos de recursos en el marco de proyectos agroindustriales, por ejemplo, la palma (Ojeda, 2016) o la caña industrial (Jaramillo et ál., 2015).

En lo que compete a nuestras búsquedas, la categoría adquiere otras connotaciones, emparentada con la idea de anales de lo cotidiano que sugieren De Certau et ál. (2010). Con esta categoría nos referimos a la manera como se concibe y vivencia una región desde la experiencia social de lo cotidiano o desde la crónica de lo existencial. La categoría enlaza con la idea de epistemología del relato local (Ruiz, 2020), que es más propia de unas memorias cercanas, y no tanto de las memorias lejanas presentes en las narrativas paradigmáticas regionales.

A estas memorias cercanas las caracteriza el énfasis en lo sensible, en lo común, en lo próximo, en lo afectivo (Arenas y Coimbra, 2016), y no tanto en los metarrelatos sociopolíticos de la trama violenta, sobre los cuales habitualmente se ha construido la interpretación de lo ocurrido en el país. No es que esto no exista, ni sea irrelevante, pero el centro de esta epistemología local es la vida en sus múltiples manifestaciones, no el hecho violento en sí mismo o la urdimbre dolorosa. En otros contextos como el Pacífico colombiano - a propósito del Proceso de Comunidades Negras - algo similar ocurre con la idea de ontologías políticas y relacionales (Escobar, 2015). Ahora bien, nuestra perspectiva es que la vida, que es a la vez personal, familiar, organizativa y comunitaria, es valorada en el Magdalena Medio de forma distinta dependiendo de si se ha sido víctima de desaparición o desplazamiento forzados. 
Para los entrevistados que vivieron en carne propia el desarraigo tras el desplazamiento forzado, con especial agudeza en esta región, entre mediados de los años noventa y comienzos de la década del 2000, cuando se habla de la vida, antes del hecho violento, indefectiblemente esta aparece vinculada a la subsistencia, al alimento cotidiano, a la tierra, a la siembra. De hecho, según uno de los entrevistados: "de lo que sembraban vivían en la finquita, de lo que sembraban, sobrevivían”. En ese sentido, "podía faltarles mucho, menos la comida, la yuca, el plátano, el maíz, las gallinas y el pescado" (Entrevista 12, 2014). Y es esa vida, recobrada en el relato, vinculada con la tierra y la comida que ella daba, y aunque sepan que no todo era idílico, la que quieren sentir de nuevo, la que desean recuperar en su presente.

En la configuración y reconfiguración de dichos paisajes cotidianos se destacan ciertas piezas invisibles para los metaanálisis políticos o sociológicos realizados habitualmente sobre la región. De hecho, es reiterativo apelar en las conversaciones a dichas trazas sentimentales para exorcizar el dolor acumulado. Y eso lo encuentran hablando, por ejemplo, de la música que se escuchaba y se sigue escuchando, de los oficios que se practicaban, de la infancia vivida, de los gustos que aún se conservan. En medio de la catástrofe familiar que ha representado para una madre no saber nada de sus dos hijos desaparecidos, ella nos narró cómo la música se convirtió en su memoria sentimental, su canal afectivo cotidiano para traerlos al presente:

A mí me gusta escuchar música, me gusta la balada, por eso a veces cuando estoy en la casa le pido a mis hijos [vivos] que me pongan canciones de Maná porque me acuerdan de José y canciones de Ricardo Arjona porque me recuerdan a Juan. Yo me siento, le subo al equipo, escucho y escucho y canto para que me salga la rabia y así es que puedo llorar tranquila. (Entrevista 17, 2014)

Hallazgos

ISSN: 1794-3841 | e-ISSN: 2422-409X | DOI: https://doi.org/10.15332/2422409X 
A través de estos retazos vitales emerge la referencia constante a los afectos, como cuando al referirse a las fiestas populares que vivió, uno de los entrevistados nos comentaba con una dosis de nostalgia y alegría que en ellas "no se quedaba nadie por fuera... pues todo el mundo colaboraba, haciendo una cosa ya el uno, haciendo ya algo el otro, compartiéndose el trabajo y la vida" (Entrevista 13, 2014). Es en ese terreno de lo afectivo, de una especie de giro emocional, destacado por otros investigadores (Angarita, 2007), desde donde estas comunidades regionales resisten la precariedad institucional del Estado, gestionan cotidianamente las presiones de los actores que aún siguen haciendo rondas en los barrios donde llegaron, o las promesas de muchos de los que llegan a investigar o intervenir.

Pero estos paisajes de lo cotidiano se tornan complejos cuando se abordan desde la experiencia de la desaparición. Esto es así porque se está frente a un ámbito de lo impreciso, lo indecible, lo intraducible, ya que traer al presente el recuerdo de la persona desaparecida no es nada sencillo; de hecho, anudan muchos silencios en los familiares. No obstante, encontramos que se emplean varios repertorios cuando se quiere hacer presente a la persona desaparecida. El lenguaje es uno de ellos; así, pareciera que los familiares entrevistados intentaran exorcizar la catástrofe de la desaparición (Gatti, 2011a; 2011b) con alusiones del tipo "él es" o "ella es". Es decir, se habla del familiar desde el presente, no desde el pasado. Quien recuerda a su familiar desaparecido parecería como si quisiera recomponer la vida arrebatada, haciendo que ella vuelva a habitar la cotidianidad familiar, nombrándola desde su condición de existencia plena. Hay un fragmento que es muy diciente al respecto en el que habla una madre según lo que su hijo sigue representado en su presente -no desde lo que fue ni representó-, aunque ya no esté y no sepa absolutamente nada de su paradero: 
Mi hijo siempre es un hombre muy tierno, él desde niño lo es, quizá porque es el menor de todos mis hijos, y también el más consentido y afectuoso. También es el más flaco, sus dedos son largos y sus manos muy finas. (Entrevista 16, 2014)

Está, además, el recurso a la fotografía o el cuaderno de poemas, que se vuelve significativo para que una esposa, por ejemplo, pueda recordar su vida de pareja, pero también los altibajos de su esposo como padre o sus reflexiones más profundas de la vida. A esto se suma el recurso a los placeres favoritos del ausente, como cuando tres de las mujeres con las cuales conversamos nos comentaban que siempre recordaban a sus hijos desaparecidos:

El pescado favorito... el bocachico..., que yo se lo preparaba sudadito... o cuando se iba pal muelle los domingos a ver las embarcaciones, los pescadores y a caminar. (Entrevista 15, 2014)

Él quería hacer muchas cosas... quería ser médico, cirujano plástico... él era muy amplio... si alguien necesitaba algo, se lo daba. (Entrevista 14, 2014)

Yo siempre le tenía el almuerzo listo cuando llegaba del colegio y me acuerdo de que cuando entraba a la casa gritaba: “iMadre, ya llegó su hijo!" Definitivamente, fue un buen hijo. Terminó sus estudios de bachillerato y su meta era seguir estudiando, pero por nuestra situación económica no se había dado aún esa posibilidad. (Entrevista 16, 2014)

En realidad son muchas las piezas de esas memorias amorosas (Solarte y Rodríguez, 2017)9 desde las cuales se recompone la vida y la identidad de la persona desaparecida, piezas que habitualmente - insistimos - no cuentan para los análisis macroprocesuales regionales: el color de los ojos, los pasatiempos favoritos, si era sociable o más bien tímida; sus aspiraciones, si le gustaba bailar o se quedaba en casa, si era una persona

\footnotetext{
${ }^{9}$ Sobre este tema en el contexto argentino, véase Saporisi (2018).
} 
amiguera, lo servicial que podían llegar a ser, las picardías de infancia, los partidos de fútbol, los amaneceres de pesca, el compartir en familia, lo arduo del trabajo.

A la par que nos interesó como equipo reconocer los paisajes cotidianos recobrados en el presente, también nos convocó reconocer cómo las comunidades locales perciben e imaginan el futuro desde sus relatos. Lo primero que debemos decir es que el asunto no es fácil de discernir en regiones donde institucionalmente se han bloqueado y anulado las posibilidades de futuro. De hecho, en varias de las entrevistas sostenidas, esto se sintió en los siguientes términos: "las instituciones nos clasifican y cuantifican sin ningún impacto en nuestras vidas" (Entrevistas 3 y 5 , 2014). El enunciado, más allá de la molestia efectiva que deviene frente a la manía institucional del "manoseo", revela también que existe poca o ninguna rendición de cuentas del trabajo con las comunidades, razón por la cual tal actuar resulta poco o nada transformador en sus vidas. En esas condiciones el futuro está lleno de incertidumbre. Este desprecio institucional (estatal, académico, económico) para con las comunidades locales se ha puesto de presente en prácticas de atención/reparación o en ciertas tecnologías psicosociales del daño en algunos contextos en Colombia (López, 2013; Villa et ál., 2017).

Aun así, en las conversaciones con las comunidades se perciben los múltiples canales utilizados para sobreponerse y mantener viva la imaginación y la esperanza, pese o a contrapelo de tales bloqueos. Dos de estos recursos han sido, por una parte, el acompañamiento de tejidos organizativos cercanos, por ejemplo, colectivos como el 16 de Mayo o plataformas como la Organización Femenina Popular, el Comité Regional para la Defensa de los Derechos Humanos o el Programa de Desarrollo y Paz del Magdalena Medio; por otra, la seguridad personal y ontológica 
(Giddens, 1991) que terminan hallando en dispositivos como las comunidades de fe o el grupo familiar.

Ambos recursos, el organizativo y el vital, fungen como condiciones de posibilidad para tornar previsibles presentes donde aún existen muchos riesgos para ellos y necesidades no satisfechas para sus familias - pero donde yergue la posibilidad de la confianza en una ética de la esperanza-, algo ya detectado por otros investigadores (Angarita, 2007; Tovar, 2019). Estos recursos terminan configurando una fenomenología del afrontamiento local para las comunidades que navegan cotidianamente sus existencias e hilan su porvenir, más allá incluso de las fórmulas artificiosas que parecen reposar en la paz institucional (Castillejo, 2019) que asume que la gente desea, vive y habla siempre de ello bajo el mismo formato.

Precisamente, en las conversaciones sostenidas en barrios de Barrancabermeja como el 22 de Marzo y El Diamante, o en un corregimiento rural como Pozo Azul, el futuro imaginado por las personas es el que corresponde a lo que por derecho propio no les debería faltar en el aquí y el ahora. Si bien las conversaciones fueron realizadas en pleno proceso de paz de La Habana, el futuro al que la gente se refiere no habla, como uno probablemente esperaría, del cese de los fusiles o de lo que derivará para las personas luego de firmado el Acuerdo. Más bien dice mucho de sus urgencias cotidianas: trabajo, educación, tierra, vivienda, seguridad y felicidad para sus hijos. Una las mujeres con las cuales conversamos en el barrio El Diamante en la comuna 7 de Barrancabermeja, frente a la pregunta realizada por uno de los integrantes del equipo sobre cómo se imaginaba su futuro a cinco o diez años luego de que fuera firmado el acuerdo, nos devolvió su impresión: “¿Será que aguanto de aquí a allá?, ¿̇será que a la vuelta de diez años sí estoy yo todavía?" (Entrevista 6, 2014). 
Para ella, su futuro no está en un tiempo proyectado de manera lejana, ni es imaginado a escala institucional por una burocracia humanitaria como la Unidad para la Atención y la Reparación Integral a las Víctimas (UARIV), ni diseñado de modo conceptual por la academia. Su futuro está ubicado en una temporalidad corta, en una especie de cronología más íntima, más lenta, quizá a su medida, que es la que día a día le permite sobrevivir y tramitar el hoy y luego el mañana. Y ello no significa que estas personas no construyan con previsión su futuro o que no crean en la necesidad de la paz a mediano y largo plazo. La previsión o sensación de paz para ellos no es la que imaginan o proyectan por lo general las instituciones. Recogiendo aquí las palabras del antropólogo Sergio Visacovsky (2019), este futuro del cual nos habla la gente común y corriente

[...] no necesariamente alude a un tiempo renovado en el que las condiciones frustrantes del presente han desaparecido. No supone necesariamente una renovación profunda, un nuevo tiempo. El futuro puede consistir en la resolución de cuestiones muy concretas, vinculadas a distintas formas de alivio ante el dolor y el sufrimiento. (p. 20)

Dado que nada se presenta de forma sencilla o como algo seguro en contextos donde todavía hay presencia de actores armados y hay que convivir a diario con el miedo, y con quien lo administra sutil y ferozmente, y más aún en zonas donde hay personas que todavía no tienen los títulos de sus terrenos o propiedades, lo que se obtiene o se logra a cada momento es ya un futuro posible.

Acostumbradas las ciencias sociales a producir conceptos sofisticados o códigos maestros de legibilidad según sistemas expertos (Ruiz et ál., 2020), la respuesta de esta mujer hace un llamado a la cautela sobre lo que desde la postura sociológica, filosófica o antropológica se fabrica artificiosamente como futuro. Llama a comprender lo que nos referencia 
Visacovsky (2019), y es que lo que "determinados conjuntos sociales imaginan como futuro mejor, como respuesta a un presente crítico, puede distar enormemente de nuestros deseos como investigadores o militantes" (p. 20).

Incluso en estas conversaciones se invita a deconstruir la idea misma de imaginación social del futuro en singular. Precisamente lo que encontramos en muchos de los fragmentos revisados son diversas formas de imaginación de los futuros comunitarios e individuales. Por ejemplo, futuros de los cuales emana un deseo seco y profundo, como los que relatan algunas de las mujeres entrevistadas, quienes, frente al desplazamiento que les arrebató bienes, vidas y anhelos, expresan:

Yo espero pronto, muy pronto, tener mi casita propia, mi casita es lo que yo más quiero, para vivir cómodos, con mis hijos. (Entrevista 1, 2014) Mi sueño ahora mismo es construir mi casa en material... y por lo pronto tener una miscelánea o una papelería en mi casa, porque tengo carisma para atender a la gente. (Entrevista 2, 2014)

Por lo pronto quisiera tener cómo trabajar con mis pasteles, mis bollos. (Entrevista 5, 2014)

Futuros locales que derivan de anhelos laborales y familiares inmediatos, que garanticen, por una parte, la seguridad vital de los que son más próximos, y por otra, el sentido de respeto mínimo de aquellos con los que conviven. En estos fragmentos se percibe algo de ello:

Yo espero que mis hijos no pasen por lo mismo que yo pasé... Mi lucha ahora es sacar esas tres hijas que tengo adelante... que por lo menos ellas sean unas profesionales... que cuando yo me vaya, por lo menos no les toque la vida tan dura como me tocó a mí... Lo que le deseo ahora mismo a mi nieto es que sea un profesional, que no se detenga en sus estudios para que pueda tener cómo sobrevivir y cómo poder ayudar a su familia. (Entrevista 3, 2014) 
Mi deseo es que la gente con la que convivimos lo respete a uno y lo valore como uno es, que no lo traten mal... los "buenos días o cómo está”... eso reconforta más que cualquier otra cosa. (Entrevista 4, 2014)

No obstante, la idea de futuro, incluso la del renombrado por la psicología como proyecto de vida, también se pone entre paréntesis, con enormes signos de interrogación y desnudando el principio de esperanza que otros parecen tener:

Este no era mi proyecto de vida, mi futuro de vida. ¿Aquí qué?, ¿aquí qué tengo yo? Aquí lo que tengo son enfermedades [...] Acá cada uno va por su lado, solo egoísmo e individualidad. (Entrevista 6, 2014)

Como investigadores inmersos en múltiples formas de privilegio, incluso para idear categorías externas a la gente misma, lo anterior invita a pensar: ¿̇cómo imaginar un proyecto de vida cuando se ha perdido prácticamente todo? Precisamente, desde la experiencia misma de los familiares víctimas de desaparición forzada, la respuesta por los futuros personales o comunitarios o lo que se avizora como proyecto personal o familiar se torna ruidoso y opaco, porque la esperanza se deshace en la incertidumbre, en la medida en que con la desaparición se está, se permanece y se vive en la ausencia misma (Gatti, 2011a).

En varios de los relatos de familiares de desaparecidos el principal proyecto vital y futuro próximo, incluso la forma misma en que se percibe la reparación estatal, se enmarca en algo que no amerita rodeo alguno: conocer la verdad, saber lo que realmente le sucedió al hijo, al hermano, al nieto, a la madre desaparecida. Uno de los fragmentos es diciente al respecto:

Nosotros solo exigimos verdad y justicia... queremos la verdad de los hechos y una justicia acorde con el delito cometido iEsa es, ha sido y seguirá siendo nuestra lucha!... Ese es nuestro principal anhelo.

(Entrevista 7, 2014)

Hallazgos

ISSN: 1794-3841 | e-ISSN: 2422-409X | DOI: https://doi.org/10.15332/2422409X 
Otros relatos tensionan la esperanza de encontrar a su familiar con vida y la desesperanza e impotencia frente a la muerte, como cuando alguien nos manifestó: “¿Será que sí es cierto que él está muerto?, ¿qué tal que él aparezca?" (Entrevista 8, 2014).

En un territorio impreciso, entre la vida y la muerte, como es siempre el de la desaparición, "territorio pantanoso... donde palabras y cosas se hunden" (Gatti, 2011a, p. 99), el no saber nada acerca del cuerpo, ni haber podido realizar el proceso de duelo, ni darle el trámite de cierre a lo que ya no está, el futuro parece situarse en un duelo presente - casi infinito-, por su condición de inconcluso. Se percibe, entonces, que el futuro que realmente importa no es el propio, sino el que fue truncado, paralizado, como parece indicarnos este fragmento:

Cuando hablo de mi hermano pienso en que era una persona cargada de aspiraciones, sueños, deseos, de amor por el trabajo, ganas de estudiar y no puedo dejar de lado el hecho de que esto no lo pudo hacer. (Entrevista 9, 2014)

\section{La práctica metodológica: apuestas y preguntas en torno a lo transformador}

Si algo permitió pensar este proyecto colectivo fue la necesidad de trabajar con ejercicios de memoria que abogaran más - desde las conversaciones y los espacios colaborativos de taller- por activar las percepciones en torno a la esperanza local y la ilusión individual y colectiva para enfrentar cotidianamente las incertidumbres. Sin embargo, ¿̇cómo evidenciar esto en las prácticas investigativas mismas? Para responder a ello nos parece pertinente situarnos en la apuesta y las preguntas que resuenan como equipo.

Los ejercicios investigativos con comunidad parten, en su gran mayoría, de la premisa de no emplear formatos pesados y prácticas extractivas, y 
debido a ello optan por metodologías denominadas participativas, colaborativas, horizontales o solidarias, que faciliten la interacción y el intercambio. De este modo, combinan en la artesanía de trabajo diversas estrategias: acuerdos locales de trabajo, entrevistas semiestructuradas, conversaciones personales y pausadas, conversaciones grupales y talleres de diverso tipo, entre otras ${ }^{10}$. Nuestro proyecto optó por este camino, no tanto porque estas metodologías fueran las más innovadoras en clave de memorias transformadoras, sino porque permitían conversar con más flexibilidad y solvencia sobre la vida social y la cotidianidad local.

La mayoría de las conversaciones, si bien no siguieron un formato estándar, permitieron un mapeo temporal tanto del espacio experiencial como del horizonte de expectativas de las personas, algo de lo cual ya hablamos en la primera parte de este escrito. Además de las entrevistas, se hicieron líneas del tiempo (figura 2) que ayudaron a reconocer ciertos códigos, también enunciados por las narrativas expertas, pero desde la evocación cronológica subjetiva, por ejemplo, las dinámicas regionales de control y violencia guerrillera, la consolidación del paramilitarismo en la década de los noventa en Magdalena Medio y las estrategias clientelistas en la política regional.

Estos recursos metodológicos facilitaron historizar ciertos hitos de resistencia organizativos apalancados por el Programa de Desarrollo y Paz del Magdalena Medio desde mediados de la década de los años noventa. A través de estos ejercicios, que fueron también complementados con árboles de la vida (figura 3) como recurso metafórico para que las comunidades evocaran sus condiciones pasadas (raíces), sus condiciones presentes (tronco) y sus aspiraciones a futuro (frutos), se logró identificar

${ }^{10}$ Sobre este asunto la literatura es bastante profusa, imposible de reseñar aquí. Dos trabajos críticos y propositivos que referenciamos son: Tuhiwai-Smith (2015) y Cornejo y Rufer (2020).

Hallazgos

ISSN: 1794-3841 | e-ISSN: 2422-409X | DOI: https://doi.org/10.15332/2422409X 
cómo se entrecruzan los hilos delgados y finos de esas microdinámicas con las hebras gruesas de la historia del conflicto armado nacional.

Otros productos fueron las historias de vida de desaparecidos y un documental. Las historias de vida se reconstruyeron fundamentalmente con información proveniente de las memorias de los familiares, y cuando no fue posible, a través de la triangulación con otras fuentes provenientes de observatorios de derechos humanos. El documental titulado El retorno de un boga ${ }^{11}$ (figura 4) se hizo con la intención de contar la historia de un agricultor, pescador y líder social de Ciénaga del Opón que, catorce años atrás, había escapado de la muerte cuando los paramilitares se apoderaron de la zona. En el documental se buscó mostrar la desintegración de su familia y cómo, a consecuencia de la violencia, este campesino se vio obligado a irse a una urbanización para desplazados en los márgenes de la zona urbana de Barrancabermeja, de la que nunca se sintió parte. La narración del documental quiso evidenciar cómo, a pesar del miedo y la incertidumbre, este protagonista, junto a otros desplazados, decidieron volver al lugar donde pertenecían y empezar de nuevo, buscar posibilidades de transformación personal y comunitaria. Con una duración de 55 minutos, el documental fue lanzado en Barrancabermeja, en Ciénaga del Opón y en Bogotá en septiembre de 2015. 11 La dirección del documental fue de Laurent J. Hernández. El término boga se refiere
a la persona que maneja una pequeña embarcación. 
Figura 2. Línea de tiempo facilitada en San Pablo, Sur de Bolívar

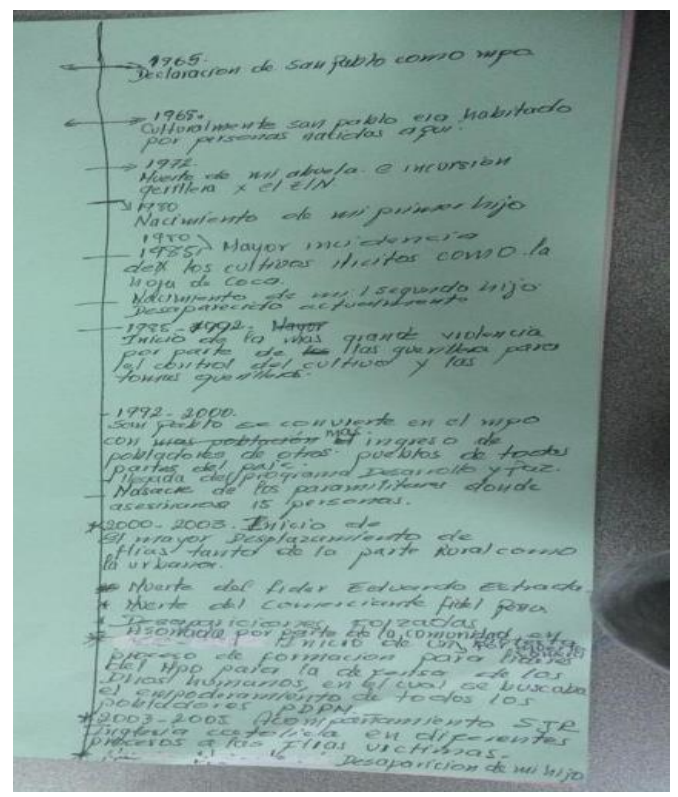

Fuente: archivo del proyecto (2014-2017).

\section{Hallazgos}

ISSN: 1794-3841 | e-ISSN: 2422-409X | DOI: https://doi.org/10.15332/2422409X

Vol. 18 N.o 36| julio-diciembre del 2021 
Figura 3. Árboles de la vida elaborados en Pozo Azul, San Pablo, Sur de Bolívar
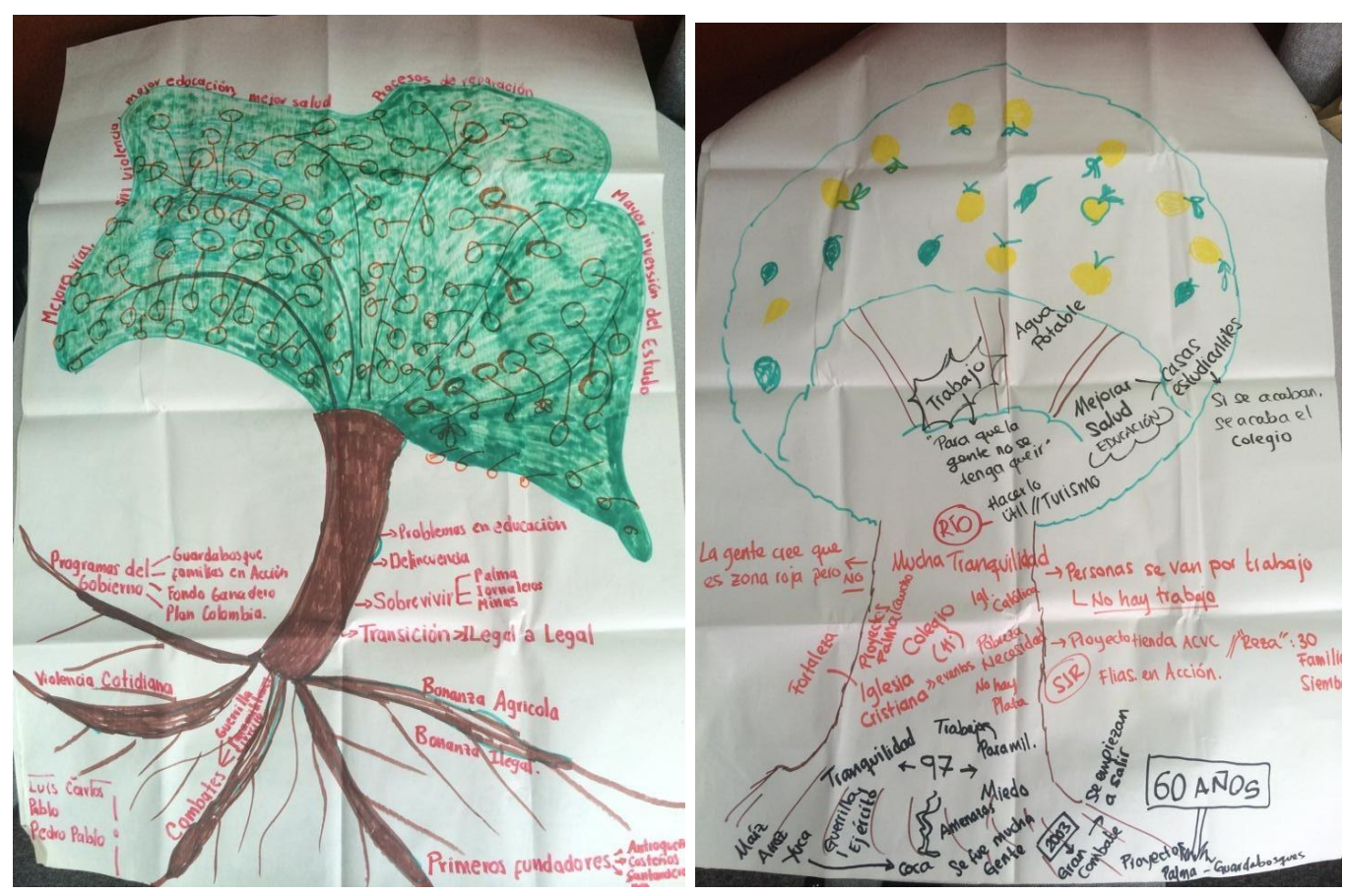

Fuente: archivo del proyecto (2014-2017).

\section{Hallazgos}

ISSN: 1794-3841 | e-ISSN: 2422-409X | DOI: https://doi.org/10.15332/2422409X

Vol. 18 N.o 36| julio-diciembre del 2021 
Figura 4. Imagen promocional del documental El retorno de un boga

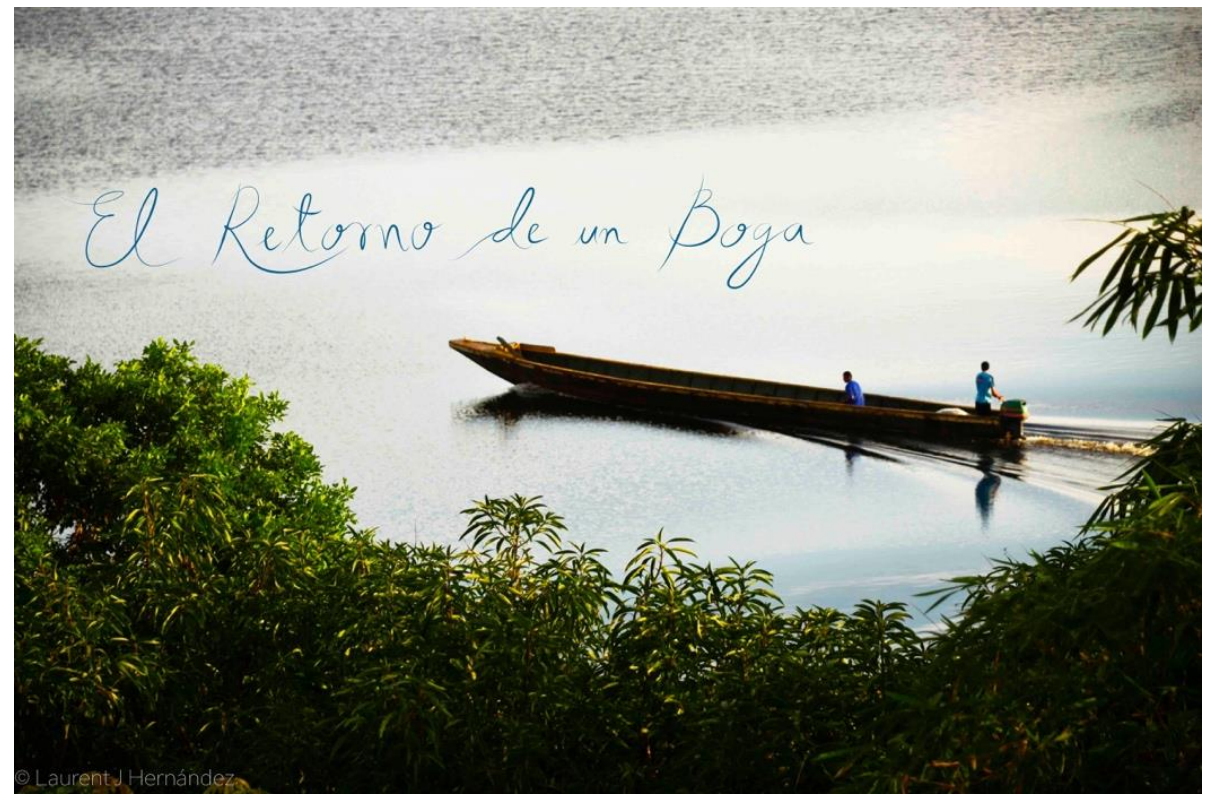

Fuente: Laurent J. Hernández (2015).

Figura 5. Cartas a futuro (a cinco años) dirigidas al presidente Santos en 2015

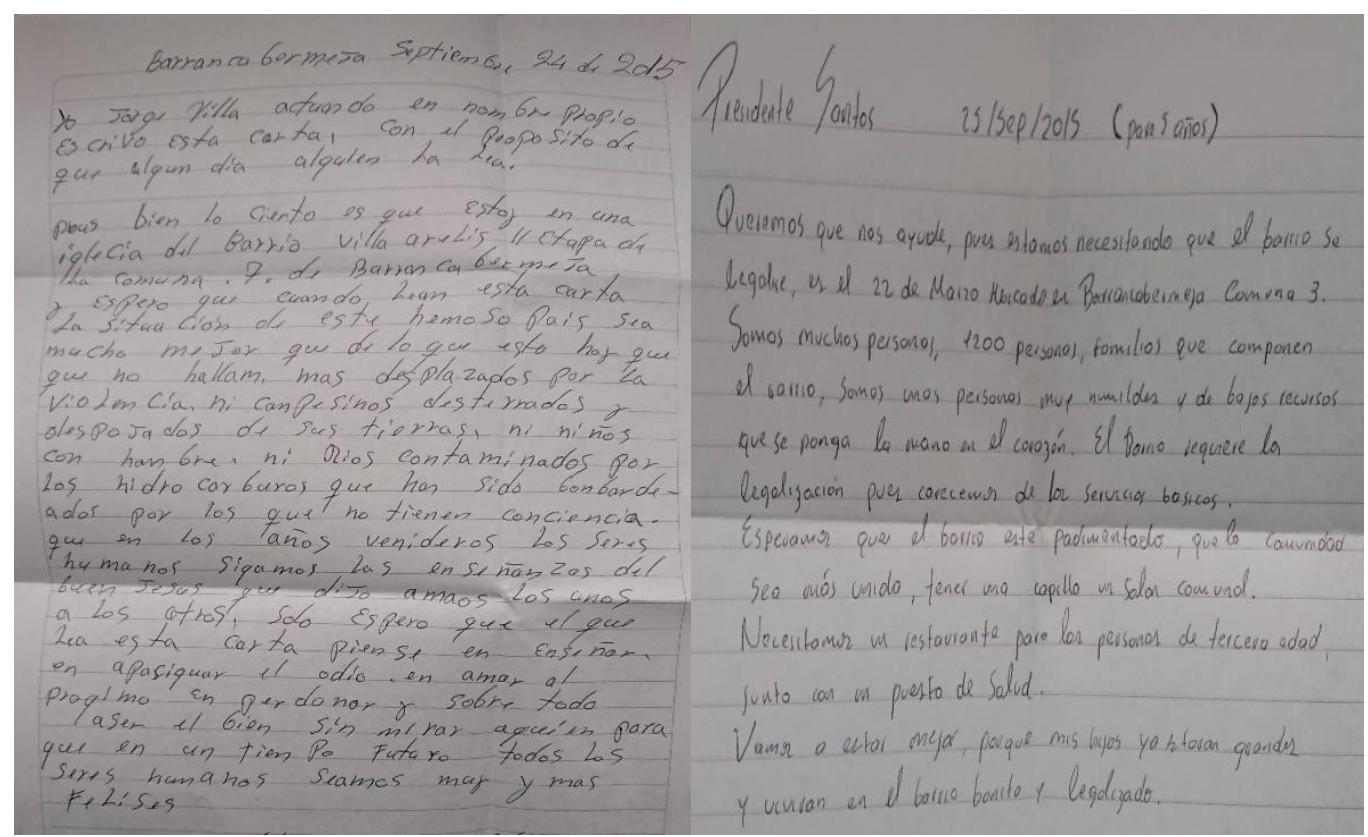

Fuente: archivo del proyecto (2014-2017).

\section{Hallazgos}

ISSN: 1794-3841 | e-ISSN: 2422-409X | DOI: https://doi.org/10.15332/2422409X

Vol. 18 N. 0 36| julio-diciembre del 2021 
Ahora bien, al hacer líneas de tiempo, cartas a futuro (figura 5), compilar relatos biográficos de personas desaparecidas y producir el documental como se propuso, el proyecto permitió responder a procesos acordados con las organizaciones locales socias. Además, todo esto se hizo con la intención de contribuir a la dignificación tanto de las personas desaparecidas como de las familias desplazadas. Sin embargo, el mayor reto planteado en la práctica fue trascender lo que con estas herramientas de uso común se logra cuando se trata de reconocer la vida en sus múltiples manifestaciones, y no solo el hecho doloroso. El tipo de historias de vida y el tipo de documental propuesto demandaron claramente propósitos diferentes a los productos sobre la memoria que habitualmente se construyen en este país, por ejemplo, el clásico informe de memoria histórica, concentrado en el hecho victimizante. Distanciarnos de relatos concentrados en la tipología de hechos, en la verdad jurídica, en el relato cronológico o en los requerimientos que hacen ciertas ONG y la cooperación internacional en su comprensión de verdad y justicia fue nuestra principal apuesta.

En el camino conversacional que se siguió para la construcción de las historias de vida de las personas desaparecidas, fuimos transitando desde un formato guía con una serie de preguntas básicas hasta una relación larga y afectuosa con cada familia. Esto nos permitió transitar luego a la entrega de un libro impreso con una historia co-construida entre la familia, el equipo del proyecto y sus socios locales. La mirada que nos interesó mantener y conservar fue sobre todo la de la memoria afectuosa sobre la vida de sus seres queridos desaparecidos, no la crónica del dolor. Esta memoria se pretende radicalmente diferente a la de una memoria justificadora o legitimadora de la desaparición por cualquier tipo de causa o a la que encapsula la vida en una arquitectura jurídica - necesaria por supuesto, pero no suficiente- del hecho de la desaparición. Esto último es 
evidente en el informe que indaga solo por el evento de la desaparición, los presuntos responsables o el proceso de denuncia de lo sucedido.

Si bien durante el proyecto le dimos mucha importancia a lo dicho, a lo enunciado a través de las conversaciones y relatos de las personas que nos apoyaron, así como también a lo que la literatura experta sobre la región ha mostrado en torno a las dinámicas regionales de victimización y resistencia, un reto que nos plantearon los ejercicios de memoria con potencial transformador es el relacionado con los silencios frente a determinados hechos. Volviendo una y otra vez a la información recabada, es evidente que hubo muchos silencios. De hecho, consideramos que los silencios funcionaron y seguirán funcionando como recursos protectores para las comunidades de cara a la persistencia y continuidad de las fracturas, a contrapelo de los cantos de sirena de la ilusión de la promesa transicional (Castillejo, 2017).

Estos silencios probablemente se asocien al miedo a perder nuevamente lo poco que han logrado volver a tener; al terror que les producen ciertos actores armados; a la desconfianza que recae sobre el Estado, pues su presencia sigue siendo muy parcial en sus cotidianidades; o a la sospecha sobre ciertos investigadores e investigadoras obstinados en saber cosas, pero sobre los que las comunidades saben muy bien que entran y salen de sus vidas rápidamente cuando termina el proyecto, quizá para retornar nunca más a estos territorios.

En ese sentido, uno de los aprendizajes de este proyecto ha sido comprender que sus silencios definitivamente dicen mucho sobre lo que no se quiere contar ni celebrar, porque duele de forma indecible, pero también revelan mucho de nosotros mismos como integrantes del equipo investigador. El riesgo está en que si nos obstinamos en comprender lo que ocurre, en querer descifrar los sinsentidos, las ambivalencias y contradicciones de estas personas, como es propio de una ciencia llana que 
busca formalizar y llenar de datos siempre los resquicios, nos convirtamos en intérpretes absolutos y, por ende, no logremos entender su sutileza, su delicadeza, pero también su crudeza y ruido (Gatti, 2011a; Aranguren, 2016).

Por último, luego de tres años largos de concluido el proyecto, son varias las preguntas que nos rebotan a los integrantes del equipo, y muy seguramente seguirán apareciendo en el camino de la investigación colectiva, pues no tenemos las respuestas decantadas para cada una. Creemos que enunciarlas permite al menos alargar la conversación entre nosotros y otros investigadores que se han enfrentado a estos procesos que se proyectan como transformadores:

- ¿Pueden los procesos investigativos colectivos y sus diversos repertorios académicos ser en sí mismos provocadores de escenarios transformadores?

- ¿Las metodologías colaborativas corren el riesgo de terminar fungiendo como lugares artificiales y cómodos para los investigadores en la medida en que las consideran útiles por el tiempo que dura el trabajo de campo o mientras se produce un artículo como este?

- ¿Cuál es la resonancia a escala local de estas metodologías y técnicas tras los procesos de devolución?

- ¿QQué tanto de la manía extractiva que se critica por doquier es realmente superada en una práctica investigativa cuando los proyectos se deben desarrollar de manera muy rápida en campo a causa de las presiones y restricciones institucionales, burocráticas o, incluso, las mismas condiciones personales?

\section{A manera de síntesis}

Este artículo ha buscado situar, desde una experiencia de trabajo investigativo en el Magdalena Medio entre 2014 y 2017, una serie de 
elementos analíticos y metodológicos que derivan de pensar en ejercicios de memoria que sean más transformadores que reconstructivos en sus apuestas comunitarias y trabajar en estos. Planteamos algunas reflexiones de manera muy sintética:

El núcleo central de las memorias locales sobre la región del Magdalena Medio en Colombia no está en el discurso macroprocesual de lo sucedido, sino en los paisajes cotidianos. Comprender la densidad de este núcleo y sus hilos y hebras quizá ayude a alivianar y reducir - no necesariamente a desaparecer- los abismos representacionales que son evidentes entre los ensambles expertos y los relatos localizados sobre las memorias regionales (Ruiz et ál., 2020).

Estos retazos de lo cotidiano no son importantes - o al menos no como deberían serlo- para los códigos expertos o las narrativas oficiales que han reconstruido gran parte de lo sucedido en esta región. En general, han sido considerados como códigos obvios por los defensores de los códigos maestros y expertos. Por tanto, habría que seguir indagando en su densidad y en la profundidad memorial de los ecos de cómo se habita, siente e imagina una región.

Los futuros comunitarios y los presentes convulsos se conectan con una necesidad de reconocimiento y de dignidad desde los anales de lo cotidiano, es decir, desde aquellas piezas en que se desglosa la crónica de la existencia común, "el peso de los días, la dificultad de vivir, o de vivir en tal o cual condición” (De Certau et ál., 2010).

El empleo de ciertos artefactos estético-políticos derivados de un proyecto en clave de memorias con potencial transformador, por ejemplo, un documental o una historia de vida, puede continuar con el fin de activar esperanzas, aunque esto no es garantía de que así sea o se logre del todo. Algo importante por mencionar es que la historia del boga se complementa 
con otros relatos cada vez que las comunidades locales ven el documental. En ese sentido, un aprendizaje en el proceso de memoria con fines transformadores ha sido el de reconocer que un viaje por la vida de un habitante de una ciénaga en particular puede también ser un viaje por la vida de quienes han tenido que afrontar el drama del desplazamiento y las marcas corporales y territoriales del despojo. El documental El retorno de un boga se ha convertido en un artefacto que abre la posibilidad de seguir completando las historias locales e imaginando colectivamente un futuro distinto para una región.

Para finalizar, son muchas las preguntas que quedan abiertas en un proyecto de memoria regional con pretensión transformadora. Si bien varias han quedado expuestas, también es necesario reconocer que previamente diversos investigadores ya las habían formulado. El llamado es a que las preguntas metodológicas inquietantes siempre estén en el centro del diseño y la implementación de proyectos con metodologías participativas, colaborativas o solidarias, sobre todo porque son estas metodologías las que, al plantear un involucramiento profundo con las comunidades, exigen discutir dilemas éticos y rutas de solución que otras metodologías no consideran. Como dice la antropóloga Laura Martínez (2019) citando a otras investigadoras: "esta es la diferencia entre éticas [metodologías] encarnadas, comprometidas y negociadas colectivamente y las éticas [metodologías] de talla única y estándar”.

\section{Sobre los autores}

Jefferson Jaramillo Marín. Doctor en Investigación en Ciencias Sociales, Flacso, México. Profesor titular del Departamento de Sociología, Pontificia Universidad Javeriana, Colombia. Su más reciente publicación es el libro titulado Defender la vida e imaginar el futuro. Debates y experiencias desde la investigación social en Buenaventura (Colombia), 
editado junto con Wooldy Edson Louidor y publicado en 2020 por la Editorial Pontificia Universidad Javeriana.

Érika Paola Parrado Pardo. Magíster en Estudios de Paz y Resolución de Conflictos por la Pontificia Universidad Javeriana, Colombia, donde actualmente es profesora de cátedra del Departamento de Historia. Su más reciente publicación se titula "Buenaventura: un escenario de geografías violentadas (1990-2017)", capítulo del libro editado por el Dr. Jefferson Jaramillo en 2020, mencionado anteriormente.

Mery Edith Rodríguez Arias. Magíster en Análisis y Resolución de Conflictos, George Mason University, Estados Unidos. Investigadora y facilitadora del Observatorio de Paz, Colombia. Su más reciente publicación es la cartilla de sistematización El territorio somos todos, la tierra es mujer. Hacia un balance de aprendizajes sobre el convenio Construyendo paz con equidad desde Nariño, publicada en 2019 por el Centro de Investigación y Educación Popular (Cinep).

Roberto Mario Solarte Rodríguez. Doctor en Filosofía por la Pontificia Universidad Javeriana, Colombia, donde actualmente es profesor asociado del Departamento de Filosofía. Su más reciente publicación es el libro Violencia e institución. Aportes para una ética de la responsabilidad social publicado en 2016 por la Editorial Pontificia Universidad Javeriana.

\section{Referencias}

Angarita, C. (2007). Cuando se hacía la fiesta todos vivíamos en comunidad. Pontificia Universidad Javeriana.

Aranguren, J. (2016). Cuerpos al límite: tortura, subjetividad y memoria en Colombia (1977-1982). Uniandes. 
Arboleda, J., Bavosi, S. y Prosser, G. (2020). El pasado en disputa: apuntes para la articulación de la memoria y los imaginarios sociales. Athenea Digital, 2O(3), 1-20. DOI: $\underline{\text { https://doi.org/10.5565/rev/athenea.2716 }}$

Archila, M., Bolívar, I., Delgado, A., García, M., González, F., Madarriaga, P., Prada, E. y Vásquez, T. (2006). Conflicto, poderes e identidades en el Magdalena Medio, 1990-2001. Cinep/Colciencias.

Arenas, S. y Coimbra, J., (2016). La memoria y la comunidad en la experiencia de vulnerabilidad. El mural de Santo Domingo Savio. Estudios Políticos, (49), 95-111. DOI: https://doi.org/10.17533/udea.espo.n49a05

Barreto, M. (2009). El Laboratorio de Paz del Magdalena Medio: ¿̇un verdadero "laboratorio de paz"? En D. Aponte y A. Restrepo (Eds.), Guerra y violencia en Colombia: herramientas e interpretaciones (pp. 501-544). Pontificia Universidad Javeriana.

Blair, E. (2011). Memoria y poder: (des)estatalizar las memorias y (des)centrar el poder del Estado. Universitas Humanística, (72), 63-87.

Belvedresi, R. (2013). ¿Puede la memoria del pasado decir algo sobre el futuro? En M. Mudrovcic y N. Rabotnikof (Coords), En busca del pasado perdido: temporalidad, historia y memoria (pp. 138-156). Siglo XXI Editores - UNAM.

Buchely, L. (2020). El Estado de la Paz: burocracias, memoria y afecto en el posconflicto colombiano. Universidad Icesi-Tirant Lo Blanch.

Castaño, D. y Jurado, P. (2019). ¿Cuál memoria? Los efectos políticos y el orden simbólico de los trabajos oficiales de memoria. Colombia Internacional, (97), 147-171. DOI: https://doi.org/10.7440/colombiaint97.2019.06

Castaño, D., Jurado, P. A. y Ruiz, G. (2018). La memoria como relato abierto. Retos políticos del trabajo de los centros de memoria. Análisis Político, 31(93), 3-19. DOI: https://doi.org/10.15446/anpol.v31n93.75614

Castillejo, A. (2017). Introducción. Dialécticas de la fractura y la continuidad: elementos para una lectura crítica de las transiciones. En A. Castillejo (Ed. y Comp.). La ilusión de la justicia transicional: perspectivas críticas desde el Sur global (pp. 156). Universidad de los Andes. 
Castillejo, A. (2019). La paz en pequeña escala: fracturas de la vida cotidiana y las políticas de la transición en Colombia. Presentación dossier. Revista de Estudios Colombianos, (53), 6-10.

Castro, X. y Erazo, C. (2019). Sufrimiento y agencia política: pesquisa sobre la condición de víctima en Bojayá, Colombia. Athenea Digital, 19(1), e2271. DOI:

https://doi.org/10.5565/rev/athenea.2271

Centro Nacional de Memoria Histórica. (2017). Memoria de la infamia: desaparición forzada en el Magdalena Medio. Autor.

Cornejo, I. y Rufer, M. (Eds). (2020). Horizontalidad: hacia una crítica de la metodología. Clacso-CALAS. https://www.clacso.org/wpcontent/uploads/2020/11/Horizontalidad.pdf

Cruz, M. (2013). El pasado, Caballo de Troya en el futuro. En M. Mudrovcic y N. Rabotnikof (Coords), En busca del pasado perdido: temporalidad, historia y memoria (pp. 157-181). Siglo XXI Editores - UNAM.

De Certau, M., Giard, L. y Mayor, P. (2010). La invención de lo cotidiano 2. Habitar, cocinar. Universidad Iberoamericana-Instituto Tecnológico y de Estudios Superiores de Occidente.

De Roux, F. (1999). El Magdalena Medio en el centro del conflicto y de la esperanza. Controversia, (174). Cinep.

Díaz, A. y Bravo, O. (Eds.) (2019). Psicología política y procesos para la paz en Colombia. Universidad Icesi/Ascofapsi.

Escobar, A. (2015). Territorios de diferencia: la ontología política de los derechos al territorio. Cuadernos de Antropología Social, (41), 25-38.

Gatti, G. (2011a). El lenguaje de las víctimas: silencios (ruidosos) y parodias (serias) para hablar (sin hacerlo) de la desaparición forzada de personas. Universitas Humanística, (72), 89-109.

Gatti, G. (2011b). Identidades desaparecidas. Peleas por el sentido en los mundos de la desaparición forzada. Prometeo.

Giddens, A. (1991). Modernity and self-identity. Self and society in the Late Modern Age. Polity. 
Gómez, D. (2013). Enfrentando el pasado, pensando el presente e imaginando otros futuros. En V. Argoty y D. Gómez (Coords.), Hescuela: Desaprendiendo para liberar (pp. 239-261). Hijos Colombia-United State Institute of Peace.

Jaramillo, J. y Torres, J. (2019). Lugares, centros y museos de memoria: boom global y marcos políticos nacionales. Anotaciones desde Colombia (2013-2015). En C. Salamanca y J. Jaramillo (Eds.), Políticas, espacios y prácticas de memoria. Disputas y tránsitos actuales en Colombia y América Latina (pp. 109-145). Pontificia Universidad Javeriana.

Jaramillo, J., Londoño, N. y Sánchez, G. (2015). Agroindustria azucarera y finca tradicional en el norte plano del Cauca (Colombia). Perspectivas históricas y claves etnográficas. Memoria y Sociedad, 19(39), 30-47.

Jelin, E. (2002). Los trabajos de la memoria. Siglo XXI Editores.

Katz, M. (2004). Experiencia regional de paz: el Programa de Desarrollo y Paz de Magdalena Medio. Controversia, (181). Cinep.

Koselleck, R. (1993). Futuros perdidos: para una semántica de los tiempos históricos. Paidós.

Lowenthal, D. (1985). El pasado es un país extraño. Akal.

López, W. (2013). El trabajo psicosocial, condición para una paz sostenible. https://www.semana.com/opinion/articulo/trabajo-psicosocial-pazsostenible $/ 358147-3 /$

Louidor, W. y Jaramillo, J. (Eds.) (2020). Defender la vida e imaginar el futuro. Debates y experiencias desde la investigación social en Buenaventura (Colombia). Pontificia Universidad Javeriana.

Martínez, L. (2019). Víctimas, salvadores y el colapso de una ONG: beneficios y riesgos de la aplicación de metodologías participativas en el trabajo de organizaciones no gubernamentales. Antípoda. Revista de Antropología y Arqueología, (35), 47-67. DOI: https://doi.org/10.7440/antipoda35.2019.03

Molano, A. (2009). En medio del Magdalena Medio. Cinep.

Molina, N. (2010). Reconstrucción de memoria en historias de vida. Efectos políticos y terapéuticos. Revista Estudios Sociales, (36), 64-75. 
Murillo, A. (1999). Historia y sociedad en el Magdalena Medio. Controversia, (174). Cinep.

http://bibliotecavirtual.clacso.org.ar/Colombia/cinep/20100917090910/Conflictot regionhistoriaysociedadenelmagdalenamedioControversiaNo17.pdf

Ojeda, D. (2016). Los paisajes del despojo: propuestas para un análisis desde las reconfiguraciones socioespaciales. Revista Colombiana de Antropología, 52(2), 1943. DOI: $\underline{\text { https://doi.org/10.22380/2539472X38 }}$

Ortega, F. (2008). Rehabitar la cotidianidad. En F. A. Ortega (Ed.), Veena Das: sujetos de dolor, agentes de dignidad (pp. 15-70). Universidad Nacional de Colombia.

Pita, R. (2016). Colonización, conflicto y cultura en la región del Magdalena Medio: entre la diversidad y la estigmatización. Temas, 3(10), 65-80.

https://doi.org/10.15332/rt.voi10.1606

Proceso de Comunidades Negras. (2015). Modelo conceptual y metodológico para la implementación de procesos de memoria histórica para comunidades y organizaciones afrodescendientes.

http://www.centrodememoriahistorica.gov.co/micrositios/comunidadesetnicas/as sets/pdf/Modelo-Conceptual-y-Metodologico.pdf

Rabe, A. (2019). La memoria no es "cosa del pasado". Los retos de la memoria en Colombia desde una perspectiva filosófica. Philosophical Readings, 11(3), 209-216, DOI: https://doi.org/10.5281/zenodo.3560346

Redepaz, Jaramillo, J. y Vera, J. (2014). Propuesta conceptual alrededor de la construcción del concepto de memoria transformadora en el marco del plan de reparación del Sujeto Colectivo Redepaz. Documento elaborado como parte del acuerdo de voluntades suscrito entre la Unidad de Atención y Reparación Integral a las Víctimas, Redepaz y Pontificia Universidad Javeriana.

https://www.academia.edu/35068006/El concepto de memoria transformador a_en_el_marco del_plan_de_reparaci\% $3 \% \mathrm{~B}_{3} \mathrm{n}$ del_Sujeto_Colectivo_REDEP $\underline{\mathrm{AZ}}$

Riaño, P. y Uribe, M. (2016). Constructing memory amidst war: The historical memory group of Colombia. International Journal of Transitional Justice, 10(1), 6-24. DOI: https://doi.org/10.1093/ijtj/ijvo36 
Ruiz, G. (2020). Memorias locales y configuración de narraciones conmemorativas: un caso de estudio en la Ciénaga Grande de Santa Marta, Colombia. Instituto Colombo-Alemán para la Paz (Capaz).

Ruiz, G., Jurado, P. y Castaño, D. (2020). Distancia representacional entre la narración experta y los relatos locales: una reflexión sobre las políticas de la evidencia en el campo de la memoria en Colombia. Antípoda. Revista de Antropología y Arqueología, (41), 103-124. DOI: http://dx.doi.org/10.7440/antipoda41.2020.05

Sánchez, G. (2014). La memoria aliada para la paz. Revista Conmemora, (4), 4-5.

Sánchez, G. (2020). Memorias, subjetividades y política: ensayos sobre un país que se niega a dejar la guerra. Planeta.

Saporisi, L. (2018). Los afectos y la memoria: sobre ¿Quién te creés que sos? de Ángela Urondo Raboy. Anclajes, 32(2), 97-114. DOI: https://doi.org/10.19137/anclajes2018-2227

Schuster, S. (2017). Memoria sin historia: una reflexión crítica acerca de la reciente "ola memorial” en Colombia. Metapolítica, (96), 44-52.

Solarte, R. (2004). Voces y silencios: paradojas de la Virgen. Theologica Xaveriana, (194), 93-118.

Solarte, R. y Rodríguez, M. (2017). Memory and identity. Ponencia presentada en el Congreso Anual del Coloquio sobre Violencia y Religión, 12 al 15 de julio. Universidad Francisco de Vitoria. https://www.academia.edu/34169615/Paper Memory and Identity

Tamayo, M. (2019). El movimiento de los derechos humanos en Colombia y la reivindicación de la memoria histórica. En C. Gómez (Comp.), Violencia y derechos humanos: México, Colombia y El Salvador (pp. 89-126). Universidad Iberoamericana.

Torres, J., Gómez, L., Fajardo, D., Salamanca, D., Grillo, M., Cubides, J., Daza, M., Vergara, T., Ortiz, D., Valencia, A., Pacheco, J., Jaramillo, J. y Torres, J. (2017). El vuelo de las gaviotas. Memorias de Colonización y resistencia afro y campesina en el Guaviare. Centro Nacional de Memoria Histórica - Consejo Comunitario Laureano Narciso Moreno - Pontificia Universidad Javeriana. 
Tovar, C. (2019). Subjetividad política para la vida y liderazgo juvenil: una iniciativa de paz desde el territorio. En A. Díaz y O. Bravo (Eds.), Psicología política y procesos para la paz en Colombia (pp. 201-244). Universidad Icesi/Ascofapsi.

Traverso, E. (2007). El pasado, instrucciones de uso. Historia, memoria, política. Marcial Pons.

Tuhiwai-Smith, L. (2015). A descolonizar las metodologías, investigación y pueblos indígenas. LOM.

Vignolo, P., Jaramillo, J. y Cabrera, M. (2017). Nota de la editora y los editores invitados: Memorias del presente y del futuro: ¿cómo, para quién, para qué? Revista Colombiana de Sociología, 4O(1), 13-21.

Villa, J., Arroyave, L., Montoya, Y. y Muñoz, A. (2017). Vicisitudes de los proyectos institucionales de atención psicosocial a víctimas del conflicto armado colombiano. Ágora, 17(1), 157-175.

Villa, J., Tejada, C., Sánchez, N. y Téllez, A. (2007). Nombrar lo innombrable: reconciliación desde la perspectiva de las víctimas. Cinep.

Visacovsky, S. (2019). Futuros en el presente: los estudios antropológicos de las situaciones de incertidumbre y esperanza. Publicar en Antropología y Ciencias Sociales, 16(26), 6-25.

Wikimedia Commons. (2020). Mapa del Magdalena Medio. https://commons.wikimedia.org/wiki/File:Mapa del Magdalena Medio.svg 